\title{
Cestrum strigilatum (Ruiz \& Pavón, 1799) B chromosome shares repetitive DNA sequences with A chromosomes of different Cestrum (Linnaeus, I753) species
}

\author{
André Luís Laforga Vanzela', Adriano Alves de Paula', Carolina Cristina Quintas', \\ Thiago Fernandes', Joana Neres da Cruz Baldissera', Thaíssa Boldieri de Souza' \\ I Laboratory of Cytogenetics and Plant Diversity, Center for Biological Sciences, State University of Londrina, \\ Londrina, 86051-980, Paraná, Brazil \\ Corresponding author: André Luis Laforga Vanzela (andrevanzela@uel.br)
}

Academic editor: J.R. Daviña | Received 26 April 2017 | Accepted 26 June 2017 | Published 3 August 2017

http://zoobank.org/099CED39-B958-497F-97AA-CA9C5C49506A

Citation: Vanzela ALL, Paula AA, Quintas CC, Fernandes T, Baldissera JNC, Souza TB (2017) Cestrum strigilatum (Ruiz \& Pavón, 1799) B chromosome shares repetitive DNA sequences with A chromosomes of different Cestrum (Linnaeus, 1753) species. Comparative Cytogenetics 11(3): 511-524. https://doi.org/10.3897/CompCytogen.v11i3.13418

\begin{abstract}
Species of Cestrum (Linnaeus, 1753) have shown large diversity in the accumulation and distribution of repetitive DNA families, and B chromosomes have been described in seven species. Some types of repetitive DNA were identified in A and B chromosomes in species of this plant group, such as AT-rich SSR, $35 \mathrm{~S}$ and $5 \mathrm{~S}$ rDNA, C-Giemsa and C-CMA/DAPI bands and retrotransposons. To increase our understanding of the relationships of A and B chromosomes, the B of C. strigilatum Ruiz \& Pavón, 1799 was microdissected, amplified and hybridized in situ against chromosomes of this species, and in six other species of this genus. FISH signals were observed in whole the $\mathrm{B}$ of $C$. strigilatum, including stretches of A chromosomes, as well as in some A chromosomes of all tested species. A strong FISH signal was seen adjacent to the $5 \mathrm{~S}$ rDNA in the proximal region of pair 8 of all species and, due to this, we have searched for $5 S$ rDNA fragments in the microdissected $\mathrm{B}$ chromosome. PCR and sequencing data evidenced $5 \mathrm{~S}$ rDNA deletion along evolutionary pathways of the $\mathrm{B}$ of $\mathrm{C}$. strigilatum. Although $\mathrm{A}$ and $\mathrm{B}$ chromosomes displayed redundancy in the repetitive DNA families in different species, the B of $C$. strigilatum seemed to differ from those Bs of other Cestrum species by the loss of rDNA fractions. A possible origin of Bs in Cestrum was discussed.
\end{abstract}

\section{Keywords}

FISH, karyotypes, microdissection, rDNA, Solanaceae, supernumerary chromosomes

Copyright A.L. Laforga Vanzela et al. This is an open access article distributed under the terms of the Creative Commons Attribution License (CC BY 4.0), which permits unrestricted use, distribution, and reproduction in any medium, provided the original author and source are credited. 


\section{Introduction}

B chromosomes have been described as additional and dispensable components of genomes, especially because they show few or no essential genes, abundance of repetitive DNA families, and independent meiotic behavior, without pairing with A chromosomes (Puertas 2002, Jones and Houben 2003). Although new information from the genomic sequencing has improved the knowledge on the $\mathrm{B}$ chromosomes of plants (Houben et al. 2014), the exact origin of these chromosomes is difficult to know, and it can be different for each genomic history. It is widely accepted that Bs arise from portions of the A complement by different pathways (Camacho et al. 2000, Jones and Houben 2003), such as chromosome rearrangements and sequence amplifications (Teruel et al. 2010, Valente et al. 2014), or after interspecific hybridizations (Navabi et al. 2011). Since B chromosomes do not exhibit Mendelian inheritance pattern, it is possible that they are maintained in populations by drive mechanisms. Such events are favored by mitotic and/or meiotic instabilities, which can provide an accumulation of Bs in different somatic and germ tissues (Burt and Trivers 2006, Jones 2012).

Approximately 24,000 species of angiosperms ( $4 \%$ of them) have Bs (Levin et al. 2005), and apparently, large genomes could favor or influence the occurrence of B chromosomes (Trivers et al. 2004). This appears to be true for some Solanaceae, since in the genus Cestrum, for example, species have 16 chromosomes with up to $12 \mu \mathrm{m}$ and 20 pg of DNA per diploid set (Paula et al. 2015), and show the highest number of taxa with Bs. These chromosomes have been reported in C. diurnum Linnaeus, 1753 (Sobti et al. 1979), C. parqui L'Héritier, $1788 \times$ C. aurantiacum Lindley, 1844 (Sýkorová et al. 2003), C. intermedium Sendtner, 1846, C. strigilatum (Fregonezi et al. 2004), C. parqui, C. euanthes Schlechtendal, 1832 and C. nocturnum Linnaeus, 1753, with 1-2, 1-3 and 1-10 B chromosomes, respectively (Urdampilleta et al. 2015). B chromosomes have also been reported for Nierembergia aristata David Don, 1833 (Solanaceae), which also has large chromosomes (Acosta and Moscone 2011).

Species of Cestrum exhibit a large variation in the occurrence and distribution of repetitive DNA families (Paula et al. 2015), and some of them have already been identified and associated with $B$ chromosomes (Fregonezi et al. 2004). In the hybrid $C$. parqui $\times$ C. aurantiacum, for instance, the $\mathrm{B}$ chromosome contains $35 \mathrm{~S}$ and $5 \mathrm{~S}$ rDNA and SSR AT-rich motifs (Sýkorová et al. 2003). Sequences of rDNA were also identified in Bs of C. parqui, C. euanthes and C. nocturnum (Urdampilleta et al. 2015). In C. intermedium and C. strigilatum, besides C-Giemsa ${ }^{+} / \mathrm{CMA}^{+} / \mathrm{DAPI}^{+}$bands (Fregonezi et al. 2004), the Bs also display hybridization signals with the Gypsy-like retrotransposons probe but not with rDNA probes (Fregonezi et al. 2007). The accumulation of data on the Bs of Cestrum (Sýkorová et al. 2003, Fregonezi et al. 2004, 2007, Fernandes et al. 2008 and Urdampilleta et al. 2015) have constantly prompted us to extend studies on the composition and behavior of these chromosomes, since this genus seems to be the main model for studies of Bs in the scope of the Solanaceae. The aim of this study 
was to understand the relationships between the $\mathrm{B}$ and $\mathrm{A}$ chromosomes of $C$. strigilatum, as well as with A chromosomes of other Cestrum species. Additionally, we have also searched any indication on presence of rDNA sequences in this $B$, in view of the existence of rDNA in Bs of other species of this genus. The discussion addresses aspects about the origin and differentiation of Bs in Cestrum.

\section{Material and methods}

Samples of Cestrum strigilatum, C. bracteatum Link \& Otto, 1828, C. corymbosum Schlechtendal, 1832, C. laevigatum Schlechtendal, 1832, C. mariquitense Kunth, 1818, C. sendtnerianum Martius, 1846, and C. schlechtendalii George Don, 1838 from Brazil are maintained in the greenhouse of the Laboratory of Cytogenetics and Plant Diversity, State University of Londrina, and vouchers are kept at the FUEL herbarium.

Root tips were pre-treated with $0.05 \%$ colchicine at room temperature for $4 \mathrm{~h}$, fixed in a solution of ethanol/acetic acid $(3: 1, \mathrm{v}: \mathrm{v})$ for up to $12 \mathrm{~h}$ and stored at $-20^{\circ} \mathrm{C}$. For conventional staining, samples were softened in $2 \%$ cellulase plus $20 \%$ pectinase (w:v) at $37^{\circ} \mathrm{C}$, hydrolyzed in $1 \mathrm{M} \mathrm{HCl}$ for $10 \mathrm{~min}$ at $60^{\circ} \mathrm{C}$, dissected in a drop of $45 \%$ acetic acid, and then squashed. Meiotic cells of $C$. strigilatum samples containing a $\mathrm{B}$ chromosome were obtained from young anthers, which were collected, directly fixed and dissected as described above. For both cases, after coverslips removal using freezing in liquid nitrogen, samples were stained in $2 \%$ Giemsa for conventional analysis and mounted with Entellan (Merck), or stored in $70 \%$ ethanol without staining when samples were for microdissection.

B chromosomes were isolated using an inverted Olympus IX71 microscope, equipped with Narishige micromanipulator. The B chromosome of $C$. strigilatum is three times smaller than those chromosomes of A set, being easily recognized and differentiated. We have dissected only those Bs that were far enough from the As, taking care to avoid contaminants. Five microdissections were made, and in each, 15 chromosomes were transferred to sterile tubes. Samples were treated with $1 \mu \mathrm{g} / \mathrm{mL}$ proteinase $\mathrm{K}$ at $60^{\circ} \mathrm{C}$ for $1 \mathrm{~h}$ and $30 \mathrm{~min}$ and the product was purified using phenol:chloroform (1:1, v:v), and quantified in a Nanodrop 2000 (Thermo). Afterwards, DNA of Bs was amplified using a Random Priming kit (Invitrogen) with biotin-14-dATP for B probe production.

Sequences of $5 \mathrm{~S}$ rDNA were amplified by PCR using as template the genomic DNA of C. strigilatum, and also a pool of 15 microdissected and purified B chromosomes of the same species. To test the reliability of reactions, three PCR repetitions were done using three different samples of microdissected B chromosomes. For this, two set of primers were used to amplify different fragments: 5S-plant-F 5'CACCGGATCCCATCAGAAACT and 5S-plant-R 5'TTAGTGCTGGTATGATCGCA, for NTS region, and UP46-F 5'GTGCGATCATACCAGCRYTAATGCACCGG and UP47-R 5' GAGGTGCAACACGAGGACTTCCCAGGAGG, for gene coding. PCR were done using a mix containing $2 \mathrm{mM} \mathrm{MgCl}_{2}, 0.4 \mu \mathrm{M}$ of each primer, 
$0.2 \mathrm{mM}$ dNTP, $0.2 \mathrm{mM}$ DNA template, $2 \mathrm{U}$ of Taq polymerase and ultrapure water to complete $25 \mu \mathrm{L}$. To probe labeling, $0.2 \mathrm{mM} \mathrm{dNTP}$ was changed by solution containing dGTP (25\%), dCTP (25\%), dTTP (25\%), dATP (17.5\%) and bio- or dig-dATP (7.5\%). When UP46 and UP47 primers were used, thermal cycler was adjusting to the following conditions: $5 \mathrm{~min}$ at $94^{\circ} \mathrm{C}$, followed by 35 cycles of $1 \mathrm{~min}$ at $94^{\circ} \mathrm{C}, 30 \mathrm{sec}$ at $60^{\circ} \mathrm{C}$ (genome the template) or $30 \mathrm{sec}$ at $50^{\circ} \mathrm{C}$ (B chromosome) and $1 \mathrm{~min}$ at $72^{\circ} \mathrm{C}$, and one end of step $5 \mathrm{~min}$ at $72^{\circ} \mathrm{C}$. When $5 \mathrm{~S}$-plant primers were used the conditions were: $5 \mathrm{~min}$ at $94^{\circ} \mathrm{C}$, followed by 35 cycles of $1 \mathrm{~min}$ at $94^{\circ} \mathrm{C}$, $40 \mathrm{sec}$ at $50^{\circ} \mathrm{C}$ (genome and $\mathrm{B}$ chromosome as template) and $1 \mathrm{~min}$ at $72^{\circ} \mathrm{C}$, and one end of step $5 \mathrm{~min}$ at $72^{\circ} \mathrm{C}$. To check the presence of $5 \mathrm{~S}$ rDNA fragments in the $\mathrm{B}$ chromosomes, both PCR products were used for FISH. The PCR products were used in a second reaction to produce templates for a Sanger sequencing, using the 3500xL Automatic Sequencer (Applied Biosystems), according to the manufacturer's procedures. For the sequencing three distinct reactions for each primer ( $F$ and $R$ ) were done, and repeated once. The consensus sequences were obtained after alignment of 12 sequences, in which quality were tested with Phred/Phrap/Consed software, and consensus sequences were contrasted against GenBank (http://www.ncbi.nlm.nih. gov/blast) to check similarities with other $5 \mathrm{~S}$ rDNA sequences. For FISH, a mixture of $30 \mu \mathrm{L}$ containing $100 \%$ formamide $(15 \mu \mathrm{L}), 50 \%$ polyethylene glycol $(6$ $\mu \mathrm{L}), 20 \times \operatorname{SSC}(3 \mu \mathrm{L}), 100 \mathrm{ng}$ calf thymus DNA $(1 \mu \mathrm{L}), 10 \%$ SDS $(1 \mu \mathrm{L})$ and 100 ng probes $(4 \mu \mathrm{L})$, was treated at $70{ }^{\circ} \mathrm{C}$ for $10 \mathrm{~min}$, placed on ice and immediately applied to the samples. $\mathrm{B}$ and $35 \mathrm{~S} \mathrm{rDNA}$ probes were labeled with biotin by random primers and nick translation, respectively. $5 \mathrm{~S}$ rDNA probes were labeled with biotin or digoxigenin by PCR. Denaturation/hybridization was performed at $95^{\circ} \mathrm{C}, 50{ }^{\circ} \mathrm{C}$ and $38^{\circ} \mathrm{C}$, ten minutes each, followed by $37^{\circ} \mathrm{C}$ overnight in a humidified chamber. Post-hybridization washes were carried out in $6 \times$ SSC and $4 \times$ SSC/0.2\% Tween 20 (> 60\% stringency), and the probes were detected using avidin-FITC (green) and anti-dig-rhodamine (red) conjugated. Post detection washes were carried out in $4 \times$ SSC/0.2\% Tween 20 at room temperature. Slides were mounted in $23 \mu \mathrm{L}$ antifade solution (90\% glycerol, 2.3\% DABCO, $2 \% 20 \mathrm{mM}$ Tris $-\mathrm{HCl}, \mathrm{pH} 8.0$, plus $1 \mu \mathrm{L}$ of $2 \mu \mathrm{g} / \mathrm{mL}$ DAPI and $1 \mu \mathrm{L}$ of $2.5 \mathrm{mM} \mathrm{MgCl}_{2}$ ).

We have analyzed at least five preparations for each species and of these, at least five metaphases. All the chromosome images were acquired in gray-scale mode using a Leica DM 4500 B microscope equipped with a DFC 300FX camera and overlapped with blue for DAPI, greenish-yellow for FITC and red for rhodamine, using Leica IM50 4.0 software. The images were optimized for contrast and brightness using the GIMP 2.8 Image Editor. To ensure hybridization of the maximum possible sequences in B and A chromosomes, we did not use pre-hybridization or blocking DNA containing excess unlabeled repetitive DNA fractions, which is generally indicated for chromosome painting procedures. This allowed us to ascertain the participation of some A complement DNA fractions in the B composition. Additionally, this allowed us to determine the presence or absence of repetitive sequences in the genomes of other closely related species. 


\section{Results and discussion}

\section{B of Cestrum strigilatum}

The screening for B chromosomes in the meiosis of Cestrum strigilatum showed that B always appears as univalent, without any kind of pairing with A chromosomes (Fig. 1a). In general, Bs of C. strigilatum appear displaced from the other chromosomes at metaphase I/anaphase I (Fig. 1a-b, see also Fregonezi et al. 2004), and more centrally located in the second stage of meiosis (Fig. 1c). The small size of the Bs (about three times less than A chromosomes), as well as the displacement from the A chromosomes, provided preparations of sufficient quality to isolate Bs using the microdissection technique, without any contamination with stretches of other chromosomes.

Chromosome painting using the microdissected B as probe was successfully employed in the Cestrum species. This procedure was previously used for chromosome painting in species of Secale Linnaeus, 1753, Allium Linnaeus, 1753 and Brachyscome Cassini, 1816 (see Houben et al. 2001), but when we compare data from literature with our case, the absence of blocking with repetitive fractions in FISH made it possible to see many signals on A chromosomes of C. strigilatum. The B chromosome of $C$. strigilatum was totally hybridized, and almost all A chromosomes of this species showed hybridization signals in different positions, such as: i) signals adjacent to C-DAPI bands, ii) lightly dispersed signals throughout the chromosomes, and iii) an intense hybridization signals associated with $5 \mathrm{~S}$ rDNA sites, in the proximal region of long arm of pair 8 (Fig. 1d-e and $2 \mathrm{~b}$ ). Of all the signals produced by the $\mathrm{B}$ chromosome-specific probe, the strong hybridization signal in the $5 \mathrm{~S}$ rDNA region (Fig. 1e) drew our attention, because previous reports indicate the absence of $5 \mathrm{~S}$ rDNA in the Bs of $C$. strigilatum and C. intermedium (Fregonezi et al. 2004). Some repetitive sequences have been described for Bs of different species of Cestrum, such as C-Giemsa ${ }^{+} / \mathrm{CMA}^{+} / \mathrm{DAPI}^{+}$bands, rDNA, SSR and Gypsy-like retrotransposons, and all of them also appeared in parts of A chromosomes (Sýkorová et al. 2003, Fregonezi et al. 2004, 2007, Urdampilleta et al. 2015). According to Houben et al. (2014), B chromosomes can be more common in species or groups of species whose genomes are involved in intense chromosomal rearrangements. Moreover, large genomes, as well as those involved with chromosome rearrangements and DNA sequence amplifications could favor the arising of B chromosomes (Trivers et al. 2004, Teruel et al. 2010, Valente et al. 2014). This seems to be the case of Cestrum species, since they exhibit large genomes and karyotypes with wide diversity in the distribution of repetitive DNA fraction (Paula et al. 2015).

\section{Detecting $5 \mathrm{~S}$ rDNA fragments on B chromosome}

Previous studies using FISH technique have shown that B of C. strigilatum carry no rDNA sequences (Fregonezi et al. 2004). On the other hand, in the B chromosomes 


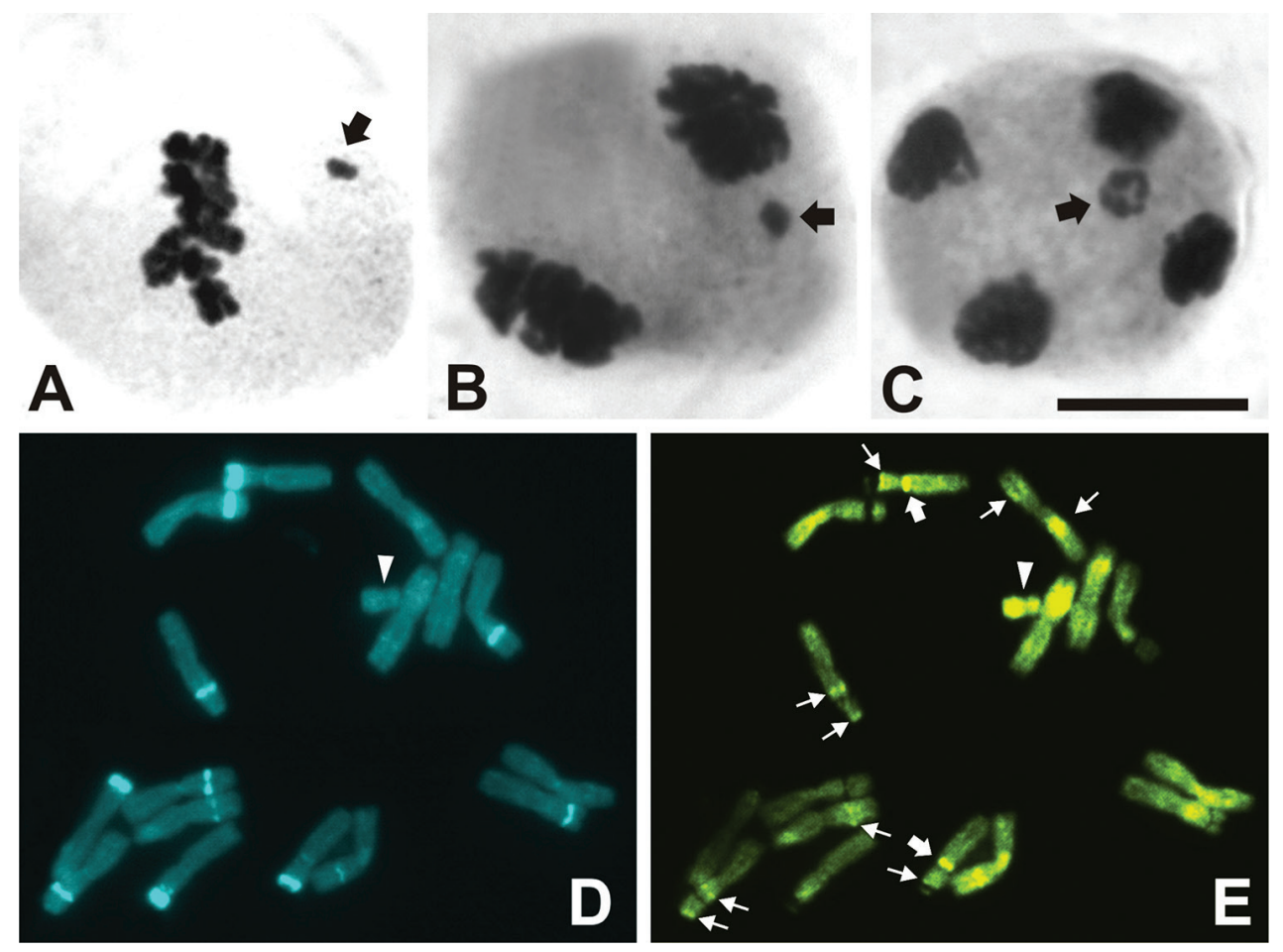

Figure I. Details of B chromosome of Cestrum strigilatum at meiosis, and FISH using the B probe against the karyotype. A Metaphase I showing the B as univalent, laterally located (arrow) B Anaphase I showing the lagging B univalent moved to one of the complements (arrow) $\mathbf{C}$ Late anaphase II close to one of the four complements. Note that the chromatids are partially separated (arrow) D Mitotic metaphase stained with DAPI. Arrowhead indicates the B E Mitotic metaphase hybridized with B probe. Note that some DAPI bands in D appear negative in E, but others do not. Large arrows indicate FISH signal colocalized with $5 \mathrm{~S}$ rDNA (see also Fig. 2), small arrows point out intercalary and terminal FISH signals, and arrowhead indicates the B completely stained by probe. $\mathrm{Bar}=10 \mu \mathrm{m}$.

of C. parqui $\times$ C. aurantiacum (Sýkorová et al. 2003) and in C. parqui, C. euanthes and C. nocturnum (Urdampilleta et al. 2015), $35 \mathrm{~S}$ and $5 \mathrm{~S}$ rDNA signals were detected. To test the colocalization of B probe signals with rDNA clusters, a double FISH using p Ta71 and pTa794 clones (containing 35 S and 5S rDNA of Triticum Linnaeus, 1753, respectively) was done after FISH with the B probe in chromosomes of $C$. bracteatum, C. corymbosum, C. laevigatum, C. mariquitense, C. sendtnerianum, C. schlechtendalii and also with $C$. strigilatum with one B. Results showed that there was no association between hybridization signals produced by the $\mathrm{B}$ and $35 \mathrm{~S} \mathrm{rDNA}$ probes in any species analyzed. Although the $\mathrm{B}$ probe signal appeared colocalized with the signal of $5 \mathrm{~S} \mathrm{rDNA}$ in C. strigilatum and in the other six species (Fig. 4a-l), the pTa794 probe containing the $5 \mathrm{~S} \mathrm{rDNA}$ fraction did not hybridize with the $\mathrm{B}$ chromosome of $C$. strigilatum (Fig. 2b, f, e). The presence of ribosomal sites on B chromosomes is not uncommon, having been reported for Bs of Crepis capillaris (Linnaeus, 1753) Wallroth, 1840, Aster- 
aceae (Maluszynska and Schweizer 1989), Nierembergia aristata, Solanaceae (Acosta and Moscone 2011) and Plantago lagopus Linnaeus, 1753, Plantaginaceae (Dhar et al. 2002). This latter species is remarkable because a large amplification of $35 \mathrm{~S}$ and $5 \mathrm{~S}$ rDNA sequences contributed to the origin of $\mathrm{B}$ chromosome. In addition, the $\mathrm{B}$ chromosome of $P$. lagopus exhibits one satDNA (named PLsatB), which represents approximately $3.3 \%$ of the genome of individuals with $\mathrm{B}$, that was originated from amplification of $5 \mathrm{~S}$ rDNA sequences (Kumke et al. 2016). At least for Cestrum, the occurrence of rDNA sequences in the Bs seems to be a plesiomorphic feature, and accordingly, the absence of $35 \mathrm{~S}$ and $5 \mathrm{~S}$ rDNA signals in the $\mathrm{B}$ of $C$. strigilatum raised an issue: Were rDNA sequences lost during $B$ chromosome differentiation in these two species or do these Bs have an independent origin, without any contribution of $\mathrm{rDNA}$ sequences?

PCR was conducted using DNA templates of the genome and microdissected B chromosome of C. strigilatum, and two distinct primer sets for amplification of different internal $5 \mathrm{~S}$ rDNA sequences were used (Fig. 2a). The UP46-F and UP47-R primers were used to amplify the coding region, and the 5S-Plant-R and 5S-Plant-F primers were used for amplification of the less-conserved NTS fragment, including a small stretch of the coding region (Fig. 3). The PCR using the UP primers and the C. strigilatum genome as template amplified a fragment with $122 \mathrm{bp}$ length, but when the $\mathrm{B}$ chromosome was used as template, the PCR product was a $97 \mathrm{bp}$ fragment (Fig. 2a). For the PCR using the 5S-Plant primers, only the genome template produced amplification, with a fragment containing 513 bp (Fig. 2a). Results of Sanger sequencing have shown three scenarios (Table 1): i) that fragment of 122 bp length of UP primers+genome exhibited high identity with a conserved $5 S$ gene coding of Vigna angularis (Willdenow) Ohwi \& Ohashi, 1969 and Lilium tsingtauense Gilg, 1904, ii) in the second, using UP primers+B template, the fragment of 97 bp length showed a partial coverage with the conserved $5 S$ gene coding of $V$. angularis and $L$. tsingtauense. When these two fragments were alingned, they exhibited $86 \%$ identity, but the $\mathrm{B}$ chromosome fragment showed two internal deletions (18 and $11 \mathrm{bp}$ in length) separated by a short $A G A(A / G) C$ motif, which seems to indicate a degeneration in the middle of the sequence (Figs 3 and $\mathrm{S} 1$ ). In the third case (5S-Plant primers+genome template), the fragment of 513 bp presented high identity with $5 \mathrm{~S}$ non transcribed sequences (NTS) of the hybrid C. aurantiacum $\times$ C. parqui and Cestrum psittacinum (Stapf, 1828) (Fig. 3 and Suppl. material 1). PCR using 5S-Plant primers using B chromosome as template produced no bands. When these three fragments were biotin-labeled and used in FISH reactions, only hybridization signals in the proximal region of the large arm of pair 8 were detected, i.e., the B chromosome of $C$. strigilatum did not exhibit any FISH signals (Fig. 2b-e).

The most reasonable explanation for the positive FISH signals with the $\mathrm{B}$ probe in the $5 \mathrm{~S} \mathrm{rDNA}$ region of $\mathrm{A}$ chromosomes, would be the presence of one or more repetitive DNA sequences associated with the $5 \mathrm{~S} \mathrm{rDNA}$. As mentioned above, there is evidence of the involvement of $5 \mathrm{~S} \mathrm{rDNA}$ in the origin of satDNA in Bs of P. lagopus (Kumke et al. 2016), but as we still isolate no the satDNA fraction in C. strigilatum, aspects on the intern organization of this $B$ is to be answered in future research. Besides 

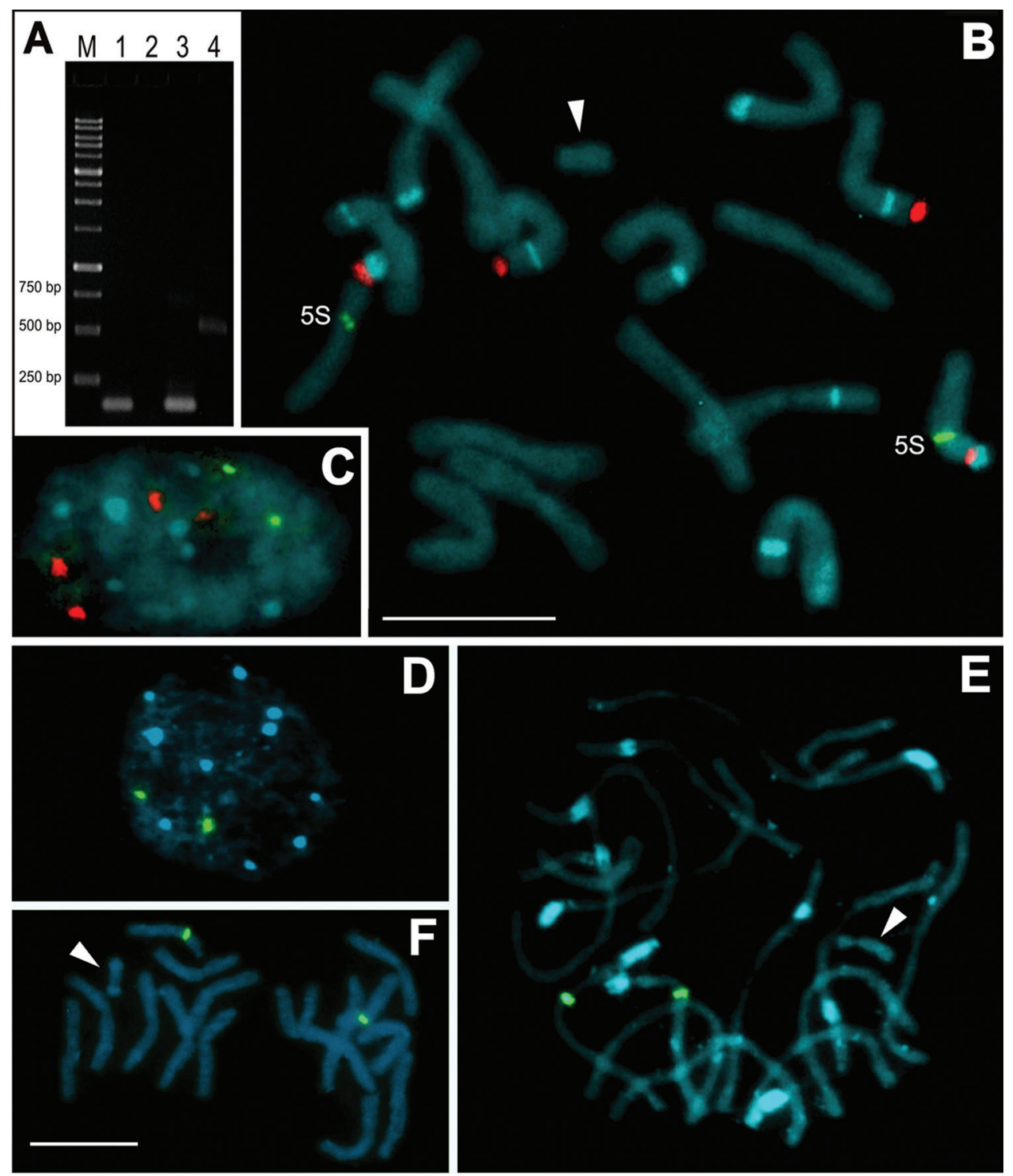

Figure 2. Detection of $5 \mathrm{~S}$ rDNA by PCR and FISH using probes produced with genomic and B chromosome DNA templates. A Electrophoresis gel containing: $\mathrm{M}=$ ladder with 250, 500, 750, $1000 \mathrm{bp}$. Lanes 1 and 3 represent fragments of about 120 bp using the UP primers using the microdissected $B$ chromosome as template (1) and the genome as template (3). Lanes 2 and 4 represent the PCR using 5S-plant primers with microdissected $\mathrm{B}$ chromosome as template (see the absence of fragment in lane 2) and with genome as template (see a fragment with about 500 bp length in lane 4 B-C Double FISH showing four hybridization sites for $35 \mathrm{~S} \mathrm{rDNA}$ using the $\mathrm{p} T a 71$ probe (red) and two sites for $5 \mathrm{~S} \mathrm{rDNA}$ using the UP primer probe of the genome (green) in the chromosomes $(\mathbf{B})$ and nucleus $(\mathbf{C})$ of $C$. strigilatum $\mathbf{D - F}$ FISH using the $5 \mathrm{~S}$ rDNA fragment amplified, using the UP primers and the microdissected B DNA as template. Note only two signals in the nucleus and prometaphase chromosomes of $C$. strigilatum (D, E respectively). Note also the absence of hybridization signals in the Bs (arrowheads). Bands in blue color represent ATrich regions identified by DAPI staining. Bar $=10 \mu \mathrm{m}$. 


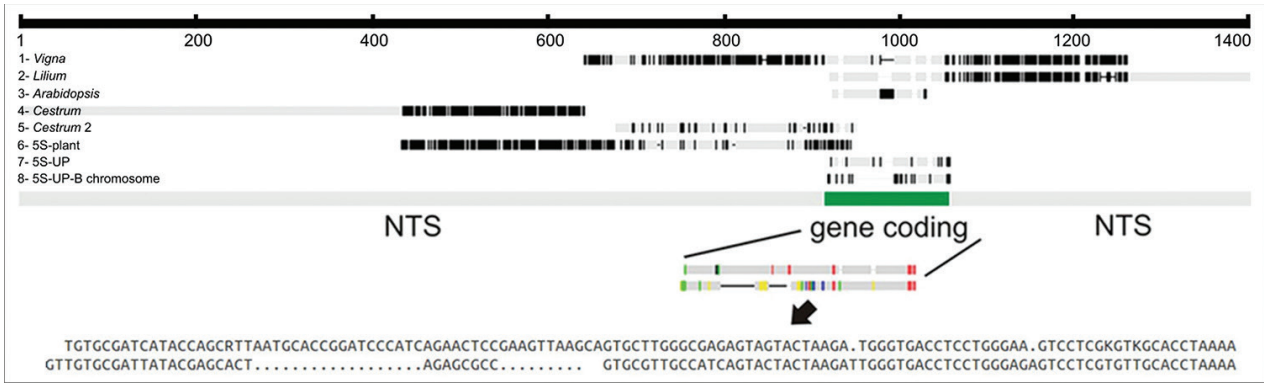

Figure 3. Diagram representing the partial alignment of $5 \mathrm{~S}$ rDNA sequences of Vigna (AP017185.1), Lilium (KM117262.1), Arabidopsis (AY130622.1), Cestrum aurantiacum $\times$ C. parqui (AY135508.1), Cestrum psittacinum (AF495752.1), 5SplantCestrum, 5SUPCestrum and 5SUP-BChrom, for location of gene coding and NTS regions. Note the two internal deletions in the $5 \mathrm{~S}$ rDNA gene coding of $\mathrm{B}$ chromosome sequence (arrow).

Table I. Results of Blast $n$ alignment using 5S-Plant and UP primers PCR products against B chromosomes and genome of Cestrum strigilatum

\begin{tabular}{|c|c|c|c|c|c|c|}
\hline Fragment & $5 S$ region & Subject & Accession & Cover & Ident. & E-value \\
\hline 5S-plant $\times$ Genome & NTS & Cestrum aurantiacum $\times$ C. parqui & AY135508.1 & $69 \%$ & $76 \%$ & $1 e-60$ \\
\hline 5S-plant $\times$ Genome & NTS & Cestrum psittacinum & AF495752.1 & $42 \%$ & $83 \%$ & $2 e-51$ \\
\hline UP×Genome & gene coding & Lilium tsingtauense & KM117262.1 & $95 \%$ & $96 \%$ & $5 e-44$ \\
\hline UP×Genome & gene coding & Vigna angularis & AP017185.1 & $95 \%$ & $96 \%$ & $5 e-44$ \\
\hline $\mathrm{UP} \times 5 \mathrm{~S}$ rDNA & gene coding & Arabidopsis thaliana & AY130622.1 & $100 \%$ & $83 \%$ & $2 e-33$ \\
\hline UP×B-chrom & gene coding & Vigna angularis & AP016873.1 & $92 \%$ & $82 \%$ & $6 e-12$ \\
\hline UP×B-chrom & gene coding & Lilium tsingtauense & KM117262.1 & $51 \%$ & $92 \%$ & $1 \mathrm{e}-07$ \\
\hline
\end{tabular}

that, $5 \mathrm{~S}$ rDNA genes can be linked with different repeated sequences, in either coding or non-coding regions, as reviewed by Roa and Guerra (2015). Our results showed that although the conserved 5S rDNA fragment was amplified by PCR using a B chromosome as template, this DNA fraction could be in small copy numbers in the Bs. Besides, since the NTS region was not amplified by PCR using the isolated B as template, it is possible that $5 \mathrm{~S}$ rDNA has been degraded in $\mathrm{B}$, preventing the visualization of FISH signals. According to Houben et al. (1999), ribosomal DNAs are very dynamic sequences and cistron number can vary between $\mathrm{B}$ and $\mathrm{A}$ chromosomes.

\section{Detecting repetitive DNA families on A chromosomes}

The B chromosome probe of C. strigilatum was also used to find complementarities in A chromosomes of six other Cestrum species (C. bracteatum, C. corymbosum, C. laevigatum, $C$. mariquitense, $C$. sendtnerianum, and $C$. schlechtendalii). FISH signals were detected in terminal, interstitial and proximal chromosome regions of these six species, but they varied in intensity, size and positioning between them. Intercalary 

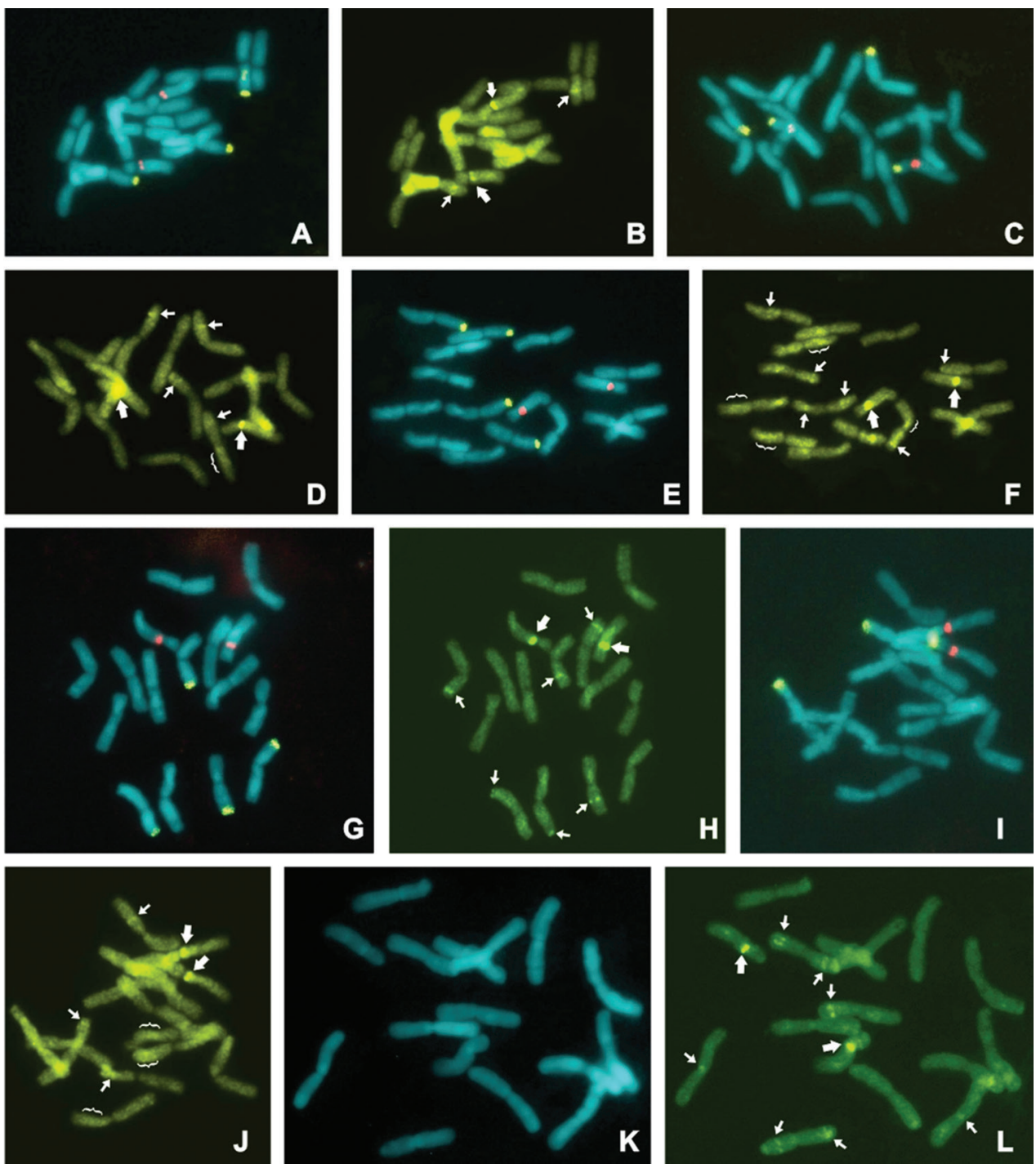

Figure 4. FISH showing the location of the $35 \mathrm{~S}$ and $5 \mathrm{~S}$ rDNA sites, and the diversity in the distribution of B probe signals in different species of Cestrum. All species showed four terminal $35 \mathrm{~S}$ rDNA signals (green) and two proximal $5 \mathrm{~S}$ rDNA signals (red). Note that in all cases, the $35 \mathrm{~S}$ probe signals did not colocalize with B probe signals, but the 5S rDNA signals did with strong signals with B probe (large arrows). A-B C. sendtnerianum: the B probe also showed intercalary signals in one chromosome pair, without evidence of scattered hybridization signals. For other species $\mathbf{C}-\mathbf{D}$ C. corymbosum $\mathbf{E}-\mathbf{F}$ C. laevigatum, (Fig. 2D) $\mathbf{G}-\mathbf{H}$ C. schlechtendalii $\mathbf{I}-\mathbf{J}$ C. bracteatum (Fig. 2H) and $\mathbf{K}-\mathbf{L}$ C. mariquitense, there was a variability in the number of intercalary hybridization signals (small arrows), besides small subterminal and terminal signals. Although all species showed scattered hybridization signals, it was more evident in chromosomes of $C$. laevigatum and $C$. bracteatum (brackets). The $\mathbf{K}$ image is only a conventional DAPI staining, without FISH with rDNA probes. Bar $=10 \mu \mathrm{m}$. 
signals were observed in one chromosome pair of C. sendtnerianum (Fig. 4b), two pairs of C. corymbosum (Fig. 4d), C. schlechtendalii (Fig. 4h) and C. mariquitense (Fig. 4l) and in three pairs of C. laevigatum (Fig. 4f) and C. bracteatum (Fig. 4j). Terminal hybridization signals were observed in one pair of $C$. laevigatum (Fig. 4f) and two pairs of C. schlechtendalii (Fig. 4h), and proximal signals were observed in one pair of $C$. mariquitense (Fig. 41). All these FISH signals with the B probe support the idea that repetitive sequences present in different parts of $A$ chromosomes may have been potentially adept to contributing for the formation and evolution of Bs. The example of Bs of Brachycome dichromosomatica (Asteraceae) is very illustrative, because the mini $\mathrm{B}$ chromosome contains a set of tandemly repetitive sequences are also found in $\mathrm{A}$ chromosomes, indicating that $\mathrm{B}$ can be involved in more than one event from the $\mathrm{A}$ complement (Houben et al. 2001, Jones and Houben 2003). Furthermore, the positive hybridization signals with this probe showed that although Cestrum species vary greatly in the distribution of repetitive DNA in karyotypes (Paula et al. 2015), some of these repetitive families are still conserved in the genus. In another example, rye B chromosomes share similar repeats with A chromosomes, differing in abundance retrotransposons (Klemme et al. 2013).

B chromosomes are generally under little or no selection pressure, and due to this, mobile elements and other repetitive DNA lineages may insert, spread, and amplify independently in these chromosomes (Houben et al. 2014). Possibly the dispensable nature of the $\mathrm{Bs}$ allowed the stronger chromosome diversification, such those reported for Bs of $C$. parqui $\times C$. aurantiacum, C. intermedium, C. strigilatum, C. parqui, C. euanthes and C. nocturnum (Sýkorová et al. 2003, Fregonezi et al. 2004, Urdampilleta et al. 2015) for the presence and location of SSR, heterochromatin, Gypsy elements and rDNA between them. This feature is in accordance with the idea of specie-specific evolutionary pathways that were mentioned for the Bs (Houben et al. 2014). However, regardless of this diversification and the independent evolutionary history within each genome, this set of information could suggest that Bs have a recent origin in Cestrum, as they appear to retain similar sizes, and also because they share repetitive sequences with complement A chromosomes between different species, although we still do not know exactly the nature of this repetitive fraction. New investments in sequencing of isolated Bs should be next steps for provided us a better understand of $\mathrm{B}$ chromosomes organization, as well as to reveal details of the repetitive sequences roles in the arising of Bs.

\section{Acknowledgments}

The authors thank the Brazilian agencies Fundacão Araucária, CNPq and CAPES for financial support. Dr. A. Leyva helped with English editing of the manuscript. 


\section{References}

Acosta MC, Moscone EA (2011) B chromosomes in Nierembergia aristata (Solanaceae): nucleolar activity and competition with the A chromosomes. Cytogenetics and Genome Research 132: 105-112. https://doi.org/10.1159/000320705

Burt A, Trivers R (2006) Genes in Conflict: the Biology of Selfish Genetic Elements. Belknap Press of Harvard University Press, Cambridge, 602 pp. https://doi.org/10.4159/9780674029118

Camacho JPM, Sharbel TF, Beukeboom LW (2000) B chromosome evolution. Philosophical Transactions of the Royal Society of London 355: 163-178. https://doi.org/10.1098/ rstb.2000.0556

Dhar M, Friebe B, Koul AK, Gill BS (2002) Origin of an apparent B chromosome by mutation, chromosome fragmentation and specific DNA sequence amplification. Chromosoma 111: 332-340. https://doi.org/10.1007/s00412-002-0214-4

Fernandes T, Yuyama PM, Moraes AP, Vanzela ALL (2008) An uncommon H3/Ser10 phosphorylation pattern in Cestrum strigilatum (Solanaceae), a species with B chromosomes. Genome 51: 772-777. https://doi.org/10.1139/G08-042

Fregonezi JN, Rocha C, Torezan JMD (2004) The occurrence of different Bs in Cestrum intermedium and C. strigilatum (Solanaceae) evidenced by chromosome banding. Cytogenetics and Genome Research 106: 184-188. https://doi.org/10.1159/000079285

Fregonezi JN, Vilas Bôas LA, Fungaro MHP, Gaeta ML, Vanzela ALL (2007) Distribution of a Ty3/gypsy-like retroelement on the A- and B-chromosomes of Cestrum strigilatum Ruiz and Pav. and Cestrum intermedium Sendtn. (Solanaceae). Genetics and Molecular Biology 30: 599-604. http://dx.doi.org/10.1590/S1415-47572007000400017

Houben A, Thompson N, Ahne R, Leach CR, Verlin D, Timmis JN (1999) A monophyletic origin of the B chromosomes of Brachycome dichromosomatica (Asteraceae). Plant Systematics and Evolution 219: 127-135. https://doi.org/10.1007/BF01090304

Houben A, Field BL, Saunders VA (2001) Microdissection and chromosome painting of plant B chromosomes. Methods in Cell Science 23: 115-124. https://doi. org/10.1023/A:1013178623270

Houben A, Banaei-Moghaddam AM, Klemme S, Timmis JN (2014) Evolution and biology of supernumerary B chromosomes. Cellular and Molecular Life Sciences 71: 467-478. https://doi.org/10.1007/s00018-013-1437-7

Jones N, Houben A (2003) B chromosomes in plants: escapees from the A chromosome genome? Trends in Plant Science 8: 417-423. http://dx.doi.org/10.1016/S1360-1385(03)00187-0 Jones N (2012) B chromosomes in plants. Plant Biosystems 146: 727-737.

Klemme S, Banaei-Moghaddam AM, Macas J, Wicker T, Novak P, Houben A (2013) Highcopy sequences reveal distinct evolution of the rye B chromosome. New Phytologist 199: 550-558. https://doi:10.1111/nph.12289

Kumke K, Macas J, Fuchs J, Altschmied L, Kour J, Dhar MK, Houben A (2016) Plantago lagopus B chromosome is enriched in 5S rDNA-derived satellite DNA. Cytogenetics and Genome Research. https://doi.org/10.1159/000444873

Levin DA, Palestris BGB, Jones RN, Trivers R (2005) Phyletic hot spots for B chromosomes in angiosperms. Evolution 5: 962-969. http://dx.doi.org/10.1554/04-148 
Maluszynska J, Schweizer D (1989) Ribosomal RNA genes in B-chromosomes of Crepis capillaris detected by non-radioactive in situ hybridization. Heredity 62: 59-65. https://doi. org/10.1038/hdy. 1989.8

Navabi ZB, Stead KE, Pires JC, Xiong Z, Sharpe AG, Parkin IAP, Rahman MH, Good AG (2011) Analysis of B-genome chromosome introgression in interspecific hybrids of Brassica napus $\times$ B. carinata. Genetics 187: 659-673. https://doi.org/10.1534/genetics.110.124925

Paula AA, Fernandes T, Vignoli-Silva M, Vanzela ALL (2015) Comparative cytogenetic analysis of Cestrum (Solanaceae) reveals different trends in heterochromatin and rDNA sites distribution. Plant Biosystems 149(6): 976-983. http://dx.doi.org/10.1080/11263504.2 014.969354

Puertas MJ (2002) Nature and evolution of B chromosomes in plants: A non-coding but information-rich part of plant genomes. Cytogenetic and Genome Research 96: 198-205. https://doi.org/10.1159/000063047

Roa F, Guerra M (2015) Non-random distribution of 5S rDNA sites and its association with $45 \mathrm{~S}$ rDNA in plant chromosomes. Cytogenetics and Genome Research 146: 243-249. https://doi.org/10.1159/000440930

Sobti SN, Verma V, Rao BL, Pushpangadan P (1979) In: IOPB chromosome number reports LXV. Taxon 28: 627.

Sýkorová E, Yoong Lim K, Fajkus J, Leitch AR (2003) The signature of the Cestrum genome suggests an evolutionary response to the loss of (TTTAGGG) ${ }_{\mathrm{n}}$ telomeres. Chromosoma 112: 164-172. https://doi.org/10.1007/s00412-003-0256-2

Teruel M, Cabrero J, Perfectti FB (2010) Chromosome ancestry revealed by histone genes in the migratory locust. Chromosoma 119: 217-225. https://doi.org/10.1007/s00412-0090251-3

Trivers R, Burt A, Palestris BGB (2004) Chromosomes and genome size in flowering plants. Genome 47: 1-8. https://doi.org/10.1139/g03-088

Urdampilleta JD, Chiarini F, Stiefkens L, Bernardello G (2015) Chromosomal differentiation of Tribe Cestreae (Solanaceae) by analyses of 18-5.8-26S and 5S rDNA distribution. Plant Systematics and Evolution 301: 1325-1334. https://doi.org/10.1007/s00606-014-1158-x Valente GT, Conte MA, Fantinatti BE, Cabral-de-Mello DC, Carvalho RF, Vicari MR, Kocher TD, Martins C (2014) Origin and evolution of B chromosomes in the cichlid fish Astatotilapia latifasciata based on integrated genomic analyses. Molecular Biology and Evolution 31(8): 2061-2072. https://doi.org/10.1093/molbev/msu148 


\section{Supplementary material I}

\section{Figure $S 1$}

Authors: André Luís Laforga Vanzela, Adriano Alves de Paula, Carolina Cristina Quintas, Thiago Fernandes, Joana Neres da Cruz Baldissera1, Thaíssa Boldieri de Souza Data type: JPEG file

Explanation note: A) Alignment of partial sequences of $5 \mathrm{~S} \mathrm{rDNA}$ of PCR product using the UP primers with C. strigilatum genome as template and PCR product using C. strigilatum $\mathrm{B}$ chromosome as template. Note the two internal deletions in the $\mathrm{B}$ chromosome amplicon, and other indels indicating a difference of 26\%. B) Alignment of partial sequences of $5 \mathrm{~S} \mathrm{rDNA}$ of $C$. aurantiacum $\times$ C. parqui, AY135508.1 against PCR products using the $5 \mathrm{~S}$-Plant primers with $C$. strigilatum genome as template. Note an identity of $76 \%$ among them.

Copyright notice: This dataset is made available under the Open Database License (http://opendatacommons.org/licenses/odbl/1.0/). The Open Database License $(\mathrm{ODbL})$ is a license agreement intended to allow users to freely share, modify, and use this Dataset while maintaining this same freedom for others, provided that the original source and author(s) are credited.

Link: https://doi.org/10.3897/CompCytogen.v11i3.13418.suppl1 